\title{
Anti-miRNA oligonucleotides (AMOs): ammunition to target miRNAs implicated in human disease?
}

\author{
J Weiler, J Hunziker and J Hall \\ Novartis Institutes for BioMedical Research, Genome and Proteome Sciences, Basel, Switzerland
}

\begin{abstract}
MicroRNAs (miRNAs) are endogenous 19-25 nucleotide RNAs that have recently emerged as a novel class of important gene-regulatory molecules involved in many critical developmental and cellular functions. miRNAs have been implicated in the pathogenesis of several human diseases, such as neurodegenerative disorders, cancer, and more recently in viral and metabolic diseases. Unraveling the roles of miRNAs in cellular processes linked
\end{abstract}

to human diseases will lead to novel opportunities for the regulation of protein function and will help to evaluate their potential for therapeutic intervention. Approaches to interfere with miRNA function in vitro and in vivo based on synthetic anti-miRNA oligonucleotides (AMOs) are discussed in this review.

Gene Therapy (2006) 13, 496-502. doi:10.1038/sj.gt.3302654; published online 29 September 2005

Keywords: miRNA; microRNA; RNAi; antisense oligonucleotides; anti-miRNA oligonucleotide; AMO

\section{Introduction}

MicroRNAs (miRNAs) are a family of short noncoding regulatory RNA molecules expressed in a variety of different cell types from several animal species, ranging from Caenorhabditis elegans to humans, as well as in plants. ${ }^{1,2}$ The miRNA pathway serves as an important post-transcriptional regulation mechanism ${ }^{3}$ and the potential importance of miRNAs in pathologically significant pathways is increasingly appreciated. In order to investigate the potential causative roles of dysregulated miRNA processes in human disease, synthetic, chemically modified oligonucleotides to target miRNAs or their mRNA targets are proving to be powerful tools and may eventually find application in a new therapeutic mechanism.

\section{miRNA and their potential role in diseases}

The biogenesis of miRNAs is a multistep process (Figure 1). ${ }^{4}$ A primary miRNA transcript (pri-miRNA), ${ }^{5}$ which is frequently synthesized from intronic regions of proteincoding RNA polymerase II transcripts, ${ }^{6,7}$ is first processed by a protein complex containing the doublestrand (ds)-specific ribonuclease Drosha in the nucleus to produce a hairpin intermediate of $\sim 70$ nucleotide $(\mathrm{nt}) .^{8}$ This precursor miRNA (pre-miRNA) is subsequently transported by Exportin-5/Ran-GTP ${ }^{9,10}$ to the cytoplasm where it is cleaved by another dsRNA specific ribonuclease, Dicer, ${ }^{11,12}$ into miRNA duplexes. After strand

Correspondence: Dr J Weiler, Novartis Institutes for BioMedical Research, Genome and Proteome Sciences, CH-4002 Basel, Switzerland.

E-mail: jan.weiler@novartis.com

Received 29 June 2005; revised 16 August 2005; accepted 25 August 2005; published online 29 September 2005 separation of the duplexes, the mature single-stranded miRNA is incorporated into an RNA-induced silencing complex (RISC)-like ribonucleoprotein particle (miRNP). ${ }^{13-15}$ This complex inhibits translation or, depending on the degree of Watson-Crick complementarity, induces degradation of target mRNAs. ${ }^{16}$

The international miRNA Registry database ${ }^{17}$ contains more than 300 verified and putative homologues of human miRNA sequences. The increasing number and diversity of miRNAs suggests that they play a role in the regulation of many genes in key pathways in a wide variety of cellular processes such as cell cycle control, apoptosis, $^{18}$ haematopoiesis, ${ }^{2,19}$ adipocyte differentiation $^{20}$ and insulin secretion. ${ }^{21}$ There is a growing number of reports that link miRNAs to the regulation of pathways associated with human diseases such as cancer, ${ }^{22}$ neurological diseases ${ }^{23}$ and most recently also with viral $^{24}$ and metabolic diseases. ${ }^{21}$ As yet, however, there is not conclusive evidence that causatively links the malfunction of a miRNA or a miRNA target site to the development of a human disease.

Modified synthetic anti-miRNA oligonucleotides (AMOs) are useful tools in specifically inhibiting individual miRNAs, thereby helping to unravel the function of miRNAs and their targets. Similar to antisense-based oligonucleotides (ASOs), AMOs may contribute to the prioritization of pharmaceutical targets and have the potential to eventually progress into a new class of therapeutic agents.

We review here literature that associates specific miRNAs with disease and reports of how AMOs have been used to help elucidate miRNA function.

\section{miRNAs and cancer}

Cancer is a genetic disease in which mutational and/or epigenetic changes in a genome leads to stepwise 


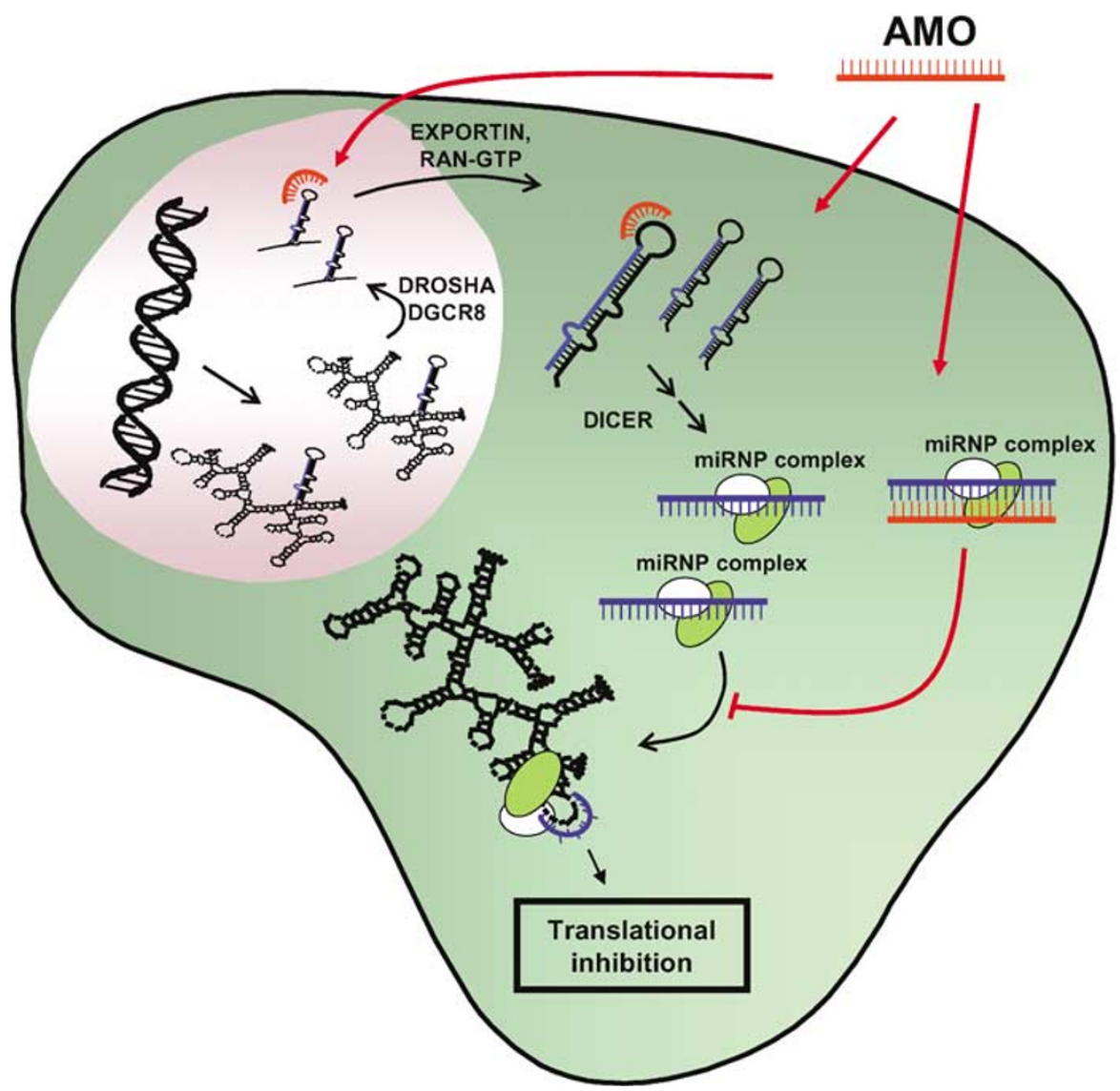

Figure 1 Interference with the miRNA pathway using synthetic oligonucleotides. Inhibition of miRNA activity may be achieved by introducing anti-miRNA oligonucleotides (AMOs) fully complementary to the pri-miRNA, the pre-miRNA or the mature miRNA.

deregulation of cell proliferation and cell death mechanisms. Evidence is emerging that particular miRNAs may play a role in human cancer pathogenesis. For example, deletions or mutations in genes that code for miRNA tumor suppressors might lead to loss of a miRNA or miRNA cluster, and thereby contribute to inappropriate stabilization of oncogenes. ${ }^{25,26}$ The results of a recent large-scale miRNA study suggest that $50 \%$ of miRNA genes are frequently located in cancer-associated genomic regions or fragile sites. ${ }^{27}$ The genes encoding mir-15 and mir-16 are located at chromosome $13 \mathrm{q} 14$, a region that is deleted in the majority of B-cell chronic lymphocytic leukemias (B-CLL), ${ }^{28}$ and in other cancers such as mantle cell lymphoma and prostate cancer. ${ }^{29}$ Interestingly, none of the protein-coding genes in this region were found to cause B-CLL, ${ }^{30}$ suggesting that mir15 and mir-16 may possibly function as tumor suppressors. MiRNAs miR-143 and miR-145 display significant downregulation in colonic adenocarcinoma samples compared to matched normal mucosa tissues. ${ }^{31}$ Putative mRNA targets of these miRNAs include several genes that have been implicated in oncogenesis such as RAF1 kinase, G-protein $\gamma 7$ and tumor-suppressing subfragment candidate 1, although molecular interaction of these genes with their putative miRNA counterparts in vivo remains to be proven.

Johnson et al. ${ }^{32}$ identified RAS, an oncogene that is overexpressed or mutated in many human cancers, as one of the genes regulated by several members of the let-
7 miRNA family. Levels of let-7a and let-7c were found to inversely correlate with RAS protein levels in matched diseased and healthy lung tissues. This correlation was experimentally confirmed in demonstrating that overexpression of a dsRNA that mimicked the let-7a precursor led to reduction of RAS whereas siRNA mediated inhibition of let-7 caused elevation of RAS in cell culture, suggesting that members of the let-7 miRNA family may safeguard against accelerated RAS expression. These findings are also consistent with earlier studies indicating that multiple let-7 genes are located in genomic regions frequently deleted in cancer patients. ${ }^{27}$ Furthermore, reduced expression of let-7 is associated with shorter postoperative survival in lung cancer patients. ${ }^{33}$

The expression of miRNA-155, which is encoded by the BIC gene, was found to be elevated in children with Burkit lymphoma. ${ }^{34}$ BIC cooperates with the oncogene $\mathrm{c}-\mathrm{Myc}$ in lymphomagenesis and erythroleukemogenesis. ${ }^{35}$ Recently, c-Myc itself has been proposed to directly activate a cluster of six miRNAs, two of them negatively regulating the transcription factor $\mathrm{E} 2 \mathrm{~F} 1$, suggesting a new mechanism by which c-Myc tightly controls cell proliferation in a cell-type specific manner. ${ }^{36}$ In another recent study, ${ }^{37}$ an miRNA cluster was suggested to act as an oncogene. The mir-17-92 polycistron cluster, which is located on a DNA fragment that is amplified in human B-cell lymphomas promoted tumor development when overexpressed in a mouse B-cell lymphoma model. 


\section{Viral miRNAs and human miRNAs targeted against viral genes}

In small-sized viral genomes, miRNAs offer an efficient means to specifically inactivate host cell defense factors compared to virally encoded proteins. Several recent reports describe miRNAs cloned from a variety of viruses such as herpes viruses ${ }^{38,39}$ and human immunodeficiency virus 1 (HIV-1). ${ }^{40}$ Pfeffer et al. ${ }^{24}$ identified five miRNAs in Epstein-Barr virus (EBV) through cloning of RNA from latently infected Burkitt's lymphoma cells. The same group $^{39}$ also found nine miRNAs encoded by human cytomegalovirus (HCMV) and, simultaneously, with Cai et $a .^{38}$ found 11 miRNAs from Kaposi's sarcomaassociated virus (KSHV). The cloned herpes virusderived miRNAs are thought to target both viral as well as host genes. In some instances, the complementarity to the putative target mRNA is near perfect, presumably leading to target mRNA degradation. This was demonstrated for miRNAs derived from the circular dsDNA simian virus 40 (SV40), which are perfectly complementary to the early viral mRNA coding for $\mathrm{T}$ antigen and accumulate in the late stages during infection. ${ }^{41}$ The reduced expression of this nonstructural protein renders the infected cells less sensitive to lysis by cytotoxic T cells.

Computational methods predict the occurrence of miRNAs in other dsDNA viruses such as herpes simplex virus 1 and 2, variola and vaccinia virus, molluscum contagiosum virus, human adenoviruses of the subgenus $\mathrm{A}, \mathrm{B}$, and $\mathrm{D}$, and $\mathrm{BK}$ virus. ${ }^{39}$ The same authors also predicted the occurrence of miRNAs in the genome of the smaller single-stranded RNA viruses, measles virus and yellow fever virus, although in the latter case this was not confirmed by cloning. Omoto et al. ${ }^{40,42}$ identified an miRNA expressed from the HIV-1 nef-gene of AIDS patients who are long-term disease nonprogressors, and which encodes an miRNA that may suppress both Nef function and HIV-1 virulence through RNA silencing. Further putative HIV-1-derived miRNAs targeted against the $\mathrm{T}$ cell receptors CD4 and CD28, and several interleukins were proposed in a recent computational study. ${ }^{43}$ Mammalian cells lack the ability to process viral dsRNA into siRNAs for subsequent destruction of the pathogen's genomic or messenger RNA. ${ }^{44}$ Instead, human miRNAs may provide an antiviral defense, as postulated recently by Lecellier et al. Working with human cells lines infected with the retrovirus primate foamy virus 1 (PFV-1), they observed that blocking miR32 with a complementary, modified oligonucleotide leads to near doubling of the PFV-1 replication rate. Sequence analysis of the genomes of 8 viruses from different families suggests that this mechanism might represent a widespread feature of host-virus interactions. ${ }^{45}$

In yet another twist to the interplay between host cell and virus, Lecellier et al. ${ }^{45}$ also demonstrated that PFV-1 expresses a protein factor, Tas, which suppresses miRNA-directed functions in mammalian cells and also displays antisilencing activities in plants. HIV-1 has evolved a similar suppressor of RNA silencing, the Tat protein which besides its transactivating function inactivates human Dicer. Another adenovirus-derived inhibitor of RNA silencing has also been described. ${ }^{46}$ The approximately 160-nt VA1 noncoding RNA is highly structured, and is expressed in adenovirus-infected cells.
It potently inhibits RNA silencing induced by shRNAs or human miRNA precursors, but does not affect RNA interference by synthetic siRNAs. RNA ligands that are naturally selected to bind protein targets specifically are referred to as aptamers. ${ }^{47}$ In this case, inhibition is likely due to direct binding of Dicer as well as competition for the Exportin 5 nuclear export factor.

\section{miRNAs in metabolic diseases}

Two recent publications have described particular miRNAs as potential therapeutic targets for the treatment of diabetes and obesity. In both studies, the respective mRNA targets were predicted and subsequently experimentally validated in cellular systems. The pancreatic islet-specific mir-375 was found to modulate glucose-stimulated insulin secretion and exocytosis, by blocking the expression of myotrophin, a protein associated with neuronal secretion. ${ }^{21}$ In a similar manner, Esau et al. suggested a potential implication of miRNAs in the maturation of human adipocytes. Modified oligonucleotide complementary to miR-143 effectively suppressed adipocyte differentiation by modulation of its putative target ERK5, a protein previously known to be implicated in MAP kinase signaling pathways, but which had not yet directly been linked to adipocyte differentiation. ${ }^{20}$

\section{miRNPs in neurological and development disorders}

Fragile $X$ syndrome was probably the first human disease to be linked to a dysfunctioning of an miRNA pathway. The gene responsible for fragile $X$ syndrome, fmr1, is inactivated through expansion of a CGG triplet repeat, methylation of which silences expression of the encoded protein, FMRP (fragile $X$ mental retardation protein). FMRP is involved in synaptic plasticity and dendritic development. ${ }^{48}$ The Drosophila homolog of FMRP, dFMR1, coimmunoprecipitates with several RISC components, among them AGO2 and VIG. Moreover, dFMR1 interacts with Dicer as well as miRNAs and exogenously added siRNAs. ${ }^{49,50}$ This was also confirmed for mammalian FMRP in vivo. ${ }^{51}$

Loss or mutation of survival of motor neuron protein (SMN), a component of an miRNA containing ribonucleoprotein (RNP) complex, is thought to be the cause of spinal muscular atrophy (SMA), a disease characterized by the progressive degeneration of motor neurons. ${ }^{23}$ SMN binds to Gemin3 in a RNP complex also consisting of Gemin4, eIF2C2 and various miRNAs. ${ }^{52}$ This complex, which may be representative for the core of human RISC, was shown to cleave RNA substrates complementary to its constituent miRNA. ${ }^{13}$

Dostie et al..$^{23}$ have cloned a miRNA from Weri human retinoblastoma cells with a potential genetic link to two other neurological diseases, namely early onset parkinsonism (Waisman syndrome) and X-linked mental retardation (MRX3). Precursors to miR-224 and a second putative miRNA were found within an EST coding for the epsilon subunit of the GABA A receptor, whose genetic locus had previously been implicated in these diseases. 
Numerous miRNAs are involved in developmental regulation of gene expression in model organisms. ${ }^{1}$ DiGeorge syndrome is a rare congenital disease whose symptoms vary but include heart defects and characteristic facial features. It is caused by a large deletion from chromosome 22 and two recent studies revealed that dgcr8, a gene located within the deleted region, encodes a protein which interacts with Drosha during the processing of primary miRNA transcripts. ${ }^{53,54}$ How this loss of activity relates to DiGeorge syndrome has not been described in detail, however.

\section{Targeting miRNA regulation with oligonucleotides}

Oligonucleotide analogs are the natural choice of therapeutic class to correct the aberrant activity of any miRNA-mRNA interaction, which contributes causally to a disease.

Where a deletion or a loss-of-function mutation is present in the miRNA gene itself, ${ }^{27,55}$ a therapeutic approach could entail exogenous delivery of corrective synthetic miRNAs in the form of (siRNA-like) dsRNA. This principle was first demonstrated in vitro by Zeng et al., ${ }^{56}$ who showed in a model system that partially complementary siRNAs can inhibit target mRNAs by miRNA-like translational inhibition. Given the vulnerability of unmodified dsRNA to nucleases in vivo, this class of compound could probably only be used in privileged local environments, for example in the central nervous system. ${ }^{57}$

If a disease phenotype is derived from abnormal inhibition of mRNAs caused by, for example, excessive expression of miRNAs, AMOs complementary to either the mature miRNA or its precursors ${ }^{58}$ can be designed (Figure 1). The earliest report of miRNA inhibition using AMOs describes the microinjection of DNA oligonucleotides of the same length and complementary to the target miRNA into Drosophila embryos. ${ }^{59}$ Unmodified DNA oligonucleotides were later found to be ineffective as inhibitors of let-7 miRNA in C. elegans, ${ }^{60}$ consistent with the known instability of unmodified DNA in vivo. Fully chemically modified oligonucleotides have previously been shown to be effective inhibitors of both coding and noncoding RNAs in vitro and in vivo (vide infra) and some of them such as an 20-mer phosphorodiamidate morpholino oligomer targeting c-Myc are currently under investigation in human clinical trials. ${ }^{61}$ The most important property of such oligonucleotides is specificity and high binding affinity to RNA. From years of antisense research, a number of nucleoside modifications emerged, which yield increased binding affinity for RNA. In particular, the addition of chemical groups to the 2'-hydroxyl group has been rather fruitful ${ }^{62}$ and a number of corresponding oligonucleotide derivatives are being pursued in clinical development and, therefore, may also be applicable as therapeutic AMOs. The following discussion is restricted to those types of modified oligonucleotides that have already been used as AMOs (Figure 2).

\section{2'-O-Methyl AMOs}

The 2'-O-methyl-group (OMe) is one of the oldest, simplest and most often used modifications to oligonucleotides. The methyl group contributes a limited amount of nuclease resistance, and improves binding affinity to RNA compared to unmodified sequences. Fully-modified OMe-oligonucleotides have been used to correct aberrant exon splicing in cells, ${ }^{63}$ and mixed backbone OMe/DNA hybrid antisense oligonucleotides are also being pursued in clinical studies. ${ }^{64}$ Hutvágner et $a .^{60}$ successfully demonstrated inhibition of let-7 function in HeLa cells, as well as C. elegans larvae, using 31-mer OMe-AMOs. Specificity of the interaction was confirmed using an unrelated RNA species with close sequence homology. The affinity between the OMeoligonucleotide and a miRNA in a targeted RISC complex was approximately 40-fold stronger than with a fully complementary mRNA, suggesting that the protein components of the RISC complex greatly enhanced the interaction beyond mere hybridization. In

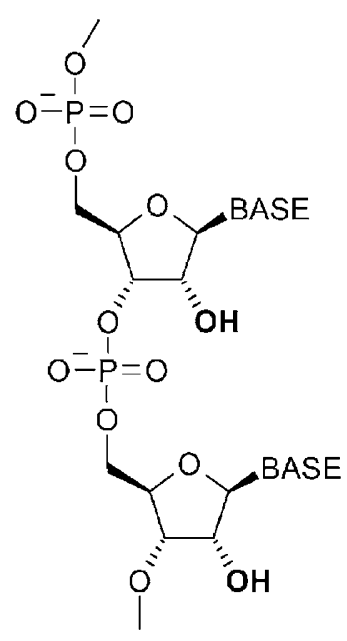

RNA

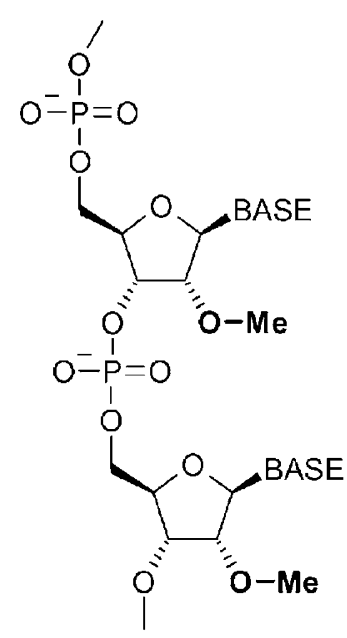

2'-OMe-RNA

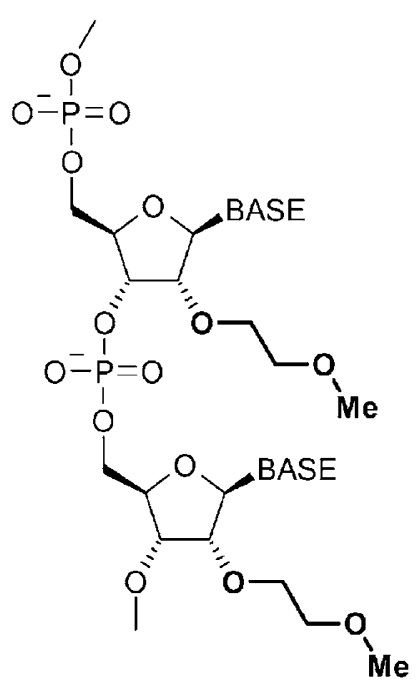

2'-MOE-RNA

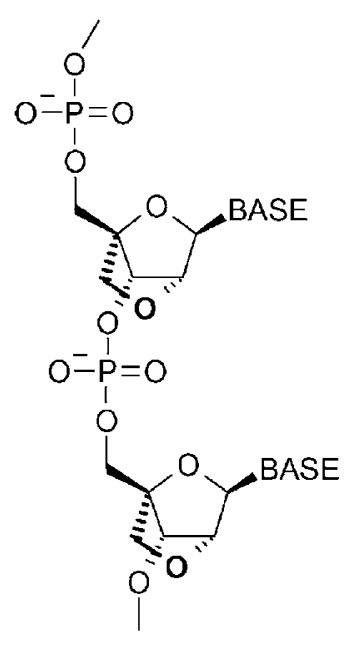

LNA

Figure 2 Chemically modified oligonucleotide analogs that have been used as anti-miRNA inhibitors (AMOs). 
two other reports, OMe-AMOs were reported to abrogate siRNA or miRNA function in cellular assays. Meister et al. ${ }^{44}$ showed that 24-mer OMe-AMOs but not natural DNA oligonucleotides could specifically abrogate miRNA function in cellular extracts as well as in cultured HeLa cells. Cheng et al. ${ }^{65}$ applied a library of Me-AMOs to human cancer cell lines to screen for miRNAs potentially involved in cell growth and apoptosis. As an alternative to direct blockage of a particular miRNA, Lee et al. ${ }^{58}$ recently suggested Me-AMOs directed against the loop region of a miRNA precursor as tools to determine miRNA function in vivo.

\section{2'-O-Methoxyethyl AMOs}

2'-O-Methoxyethyl (MOE)-modified oligonucleotides have higher affinity and specificity to RNA than their OMe-analogs. ${ }^{66}$ They have been used effectively as fully modified oligonucleotides targeted to re-direct mRNA splicing ${ }^{67}$ and also as inhibitors of protein translation. ${ }^{68}$ MOE-ASOs represent an increasing proportion of modified oligonucleotides in clinical trials. ${ }^{69}$ Concerning their application in miRNA research, Esau et al. ${ }^{20}$ transfected separately MOE-AMOs targeting 86 human miRNAs into cultured human preadipocytes to address the role of miRNAs in adipocyte differentiation. By following gene expression profiles of five marker genes they found miR-143 to be involved in this process through regulation of ERK5 protein levels. Treatment of adipocytes with a MOE-AMO complementary to miR-143 effectively inhibited the differentiation process, whereas negative controls were inactive. Furthermore, Northern blot analysis of cell lysates indicated that MOE-AMO treatment had also decreased levels of miR-143, presumably by inhibition of processing of the pri-miRNA by Drosha.

\section{Locked nucleic acid AMOs}

Locked nucleic acid (LNA)-modified oligonucleotides are distinctive 2'-O-modified RNA in which the $2^{\prime}-O-$ oxygen is bridged to the $4^{\prime}$-position via a methylene linker to form a rigid bicycle, locked into a C3'-endo (RNA) sugar conformation. ${ }^{70}$ The LNA modification leads to the thermodynamically strongest duplex formation with complementary RNA known. Consequently, a biological activity is often attained with very short LNA oligonucleotides. For example, an $8 \mathrm{nt}$ fullymodified LNA oligomer complementary to a structural loop inhibited $50 \%$ of self-splicing of group I introns from rRNA genes in pathogenic organisms whereas DNA and RNA oligonucleotides were ineffective. ${ }^{71}$ Short fully-modified LNA oligonucleotides designed against telomerase were active in cellular assays, compared to mismatched negative controls. ${ }^{72}$ Furthermore, LNAs display excellent mismatch discrimination. Mouritzen et al. $^{73}$ showed single-nucleotide specificity against complementary DNA using fully modified $12 \mathrm{nt}$ LNA probes coupled to glass slides during the development of a microarray used to probe samples for single-nucleotide polymorphisms (SNPs) associated with human dysmetabolic syndrome. LNA oligonucleotides have not been tested in humans, but results in rodents are promising. ${ }^{74}$ LNAs were stable and showed a serum decay and tissue distribution similar to that of phosphorothioate oligonucleotides. A fully complementary LNA oligonucleotide targeted to murine POLR2A protein was effective using continuous administration at $2.5 \mathrm{mg} / \mathrm{kg}$ with no associated liver or kidney toxicity.

LNA oligonucleotides have been used as northern probes to detect miRNAs as mixed backbone oligonucleotides. ${ }^{75}$ Excellent selectivity and sensitivity - at least 10-fold greater than with DNA - was obtained and single-nucleotide selectivity shown with a mismatch in the middle of the sequences. Mixed LNA/DNA AMOs potently abolished miR-32 function in PFV-1 infected HeLa cells and led to the accumulation of viral mRNA, resulting in increased production of viral progeny. ${ }^{45}$ Recently, Chan et al. ${ }^{76}$ have successfully applied $2^{\prime}-\mathrm{O}$ methyl- and DNA/LNA-mixed oligonucleotides to specifically knockdown miR-21 in order to investigate the potential contribution of this miRNA in the regulation of apoptosis-associated genes in glioblastoma cell lines.

\section{Conclusions}

Although the precise cellular functions of most mammalian miRNAs are still unknown, increasing evidence suggests that miRNAs regulate many biological processes associated with human disease. However, critical questions remain as to the number of existing miRNAs, how many mRNA targets are regulated by a particular miRNA and how many miRNAs control a particular mRNA target. ${ }^{77-79}$ An increasing number of highly sophisticated bioinformatics methods is being developed to identify additional putative miRNAs and their predicted miRNA target genes. ${ }^{79-81}$ In addition, the systematic application of genomics technologies such as expression profiling 82,83 in combination with loss- and gain-of-function studies in cellular models might contribute to a better understanding of miRNA controlled cellular networks and may lead to new ways of intervention in human diseases. Without doubt, AMOs have the potential to become powerful tools in interfering with miRNA pathways thereby contributing to the dissection of their functions and their putative role in human disease processes.

The promise of antisense therapeutics has yet to be fulfilled. The regulatory approval of the first generation oligonucleotide Vitravene for CMV retinitis was not followed by a rush of further approvals, yet there are still many modified ASOs in clinical trials, especially in the area of cancer treatment. ${ }^{69}$ Recently, siRNAs have reached clinical development, and the first proof of concept studies have been described, involving the local injection of dsRNA reagents into the eye. ${ }^{84,85}$ Although, the prospects for AMO therapeutics are ultimately linked to the success of these oligonucleotide-based drugs, the principal question at this point remains: will miRNAs make good therapeutic targets?

\section{Acknowledgements}

We would like to thank Iwan Beuvink for critically reading this manuscript and for valuable comments. We apologize to our colleagues whose outstanding contributions to the growing miRNA field were not cited as primary references only through space constraints. 


\section{References}

1 Ambros V. The functions of animal microRNAs. Nature 2004; 431: 350-355.

2 Bartel DP. MicroRNAs: genomics, biogenesis, mechanism, and function. Cell 2004; 116: 281-297.

3 Filipowicz W, Jaskiewicz L, Kolb FA, Pillai RS. Post-transcriptional gene silencing by siRNAs and miRNAs. Curr Opin Struct Biol 2005; 15: 331-341.

$4 \mathrm{Kim}$ VN. MicroRNA biogenesis: coordinated cropping and dicing. Nat Rev Mol Cell Biol 2005; 6: 376-385.

5 Lee Y, Jeon K, Lee JT, Kim S, Kim VN. MicroRNA maturation: stepwise processing and subcellular localization. EMBO J 2002; 21: 4663-4670.

6 Cai $\mathrm{X}$, Hagedorn $\mathrm{CH}$, Cullen BR. Human microRNAs are processed from capped, polyadenylated transcripts that can also function as mRNAs. RNA 2004; 10: 1957-1966.

7 Lee Y, Kim M, Han J, Yeom KH, Lee S, Baek SH et al. MicroRNA genes are transcribed by RNA polymerase II. EMBO J 2004; 23: 4051-4060.

8 Lee Y, Ahn C, Han J, Choi H, Kim J, Yim J et al. The nuclear RNase III Drosha initiates microRNA processing. Nature 2003; 425: 415-419.

9 Yi R, Qin Y, Macara IG, Cullen BR. Exportin-5 mediates the nuclear export of pre-microRNAs and short hairpin RNAs. Genes Dev 2003; 17: 3011-3016.

10 Lund E, Guttinger S, Calado A, Dahlberg JE, Kutay U. Nuclear export of microRNA precursors. Science 2004; 303: 95-98.

11 Bernstein E, Caudy AA, Hammond SM, Hannon GJ. Role for a bidentate ribonuclease in the initiation step of RNA interference. Nature 2001; 409: 363-366.

12 Hutvagner G, McLachlan J, Pasquinelli AE, Balint E, Tuschl T, Zamore PD. A cellular function for the RNA-interference enzyme Dicer in the maturation of the let-7 small temporal RNA. Science 2001; 293: 834-838.

13 Hutvagner G, Zamore PD. A microRNA in a multiple-turnover RNAi enzyme complex. Science 2002; 297: 2056-2060.

14 Martinez J, Patkaniowska A, Urlaub H, Luhrmann R, Tuschl T. Single-stranded antisense siRNAs guide target RNA cleavage in RNAi. Cell 2002; 110: 563-574.

15 Tang G. siRNA and miRNA: an insight into RISCs. Trends Biochem Sci 2005; 30: 106-114.

16 Yekta S, Shih IH, Bartel DP. MicroRNA-directed cleavage of HOXB8 mRNA. Science 2004; 304: 594-596.

17 Griffiths-Jones S. The microRNA Registry. Nucleic Acids Res 2004; 32: D109-D111.

18 Brennecke J, Hipfner DR, Stark A, Russell RB, Cohen SM. bantam encodes a developmentally regulated microRNA that controls cell proliferation and regulates the proapoptotic gene hid in Drosophila. Cell 2003; 113: 25-36.

19 Chen CZ, Li L, Lodish HF, Bartel DP. MicroRNAs modulate hematopoietic lineage differentiation. Science 2004; 303: 83-86.

20 Esau C, Kang X, Peralta E, Hanson E, Marcusson EG, Ravichandran LV et al. MicroRNA-143 regulates adipocyte differentiation. J Biol Chem 2004; 279: 52361-52365.

21 Poy MN, Eliasson L, Krutzfeldt J, Kuwajima S, Ma X, Macdonald PE et al. A pancreatic islet-specific microRNA regulates insulin secretion. Nature 2004; 432: 226-230.

22 Gregory RI, Shiekhattar R. MicroRNA biogenesis and cancer. Cancer Res 2005; 65: 3509-3512.

23 Dostie J, Mourelatos Z, Yang M, Sharma A, Dreyfuss G. Numerous microRNPs in neuronal cells containing novel microRNAs. Rna 2003; 9: 180-186.

24 Pfeffer S, Zavolan M, Grasser FA, Chien M, Russo JJ, Ju J et al. Identification of virus-encoded microRNAs. Science 2004; 304: 734-736.

25 McManus MT. MicroRNAs and cancer. Semin Cancer Biol 2003; 13: $253-258$
26 Gong H, Liu CM, Liu DP, Liang CC. The role of small RNAs in human diseases: potential troublemaker and therapeutic tools. Med Res Rev 2005; 25: 361-381.

27 Calin GA, Sevignani C, Dumitru CD, Hyslop T, Noch E, Yendamuri $\mathrm{S}$ et al. Human microRNA genes are frequently located at fragile sites and genomic regions involved in cancers. Proc Natl Acad Sci USA 2004; 101: 2999-3004.

28 Calin GA, Dumitru CD, Shimizu M, Bichi R, Zupo S, Noch E et al. Frequent deletions and down-regulation of micro-RNA genes miR15 and miR16 at 13q14 in chronic lymphocytic leukemia. Proc Natl Acad Sci USA 2002; 99: 15524-15529.

29 Stilgenbauer S, Nickolenko J, Wilhelm J, Wolf S, Weitz S, Dohner $\mathrm{K}$ et al. Expressed sequences as candidates for a novel tumor suppressor gene at band 13q14 in B-cell chronic lymphocytic leukemia and mantle cell lymphoma. Oncogene 1998; 16: 1891-1897.

30 Migliazza A, Cayanis E, Bosch-Albareda F, Komatsu H, Martinotti S, Toniato E et al. Molecular pathogenesis of B-cell chronic lymphocytic leukemia: analysis of 13q14 chromosomal deletions. Curr Top Microbiol Immunol 2000; 252: 275-284.

31 Michael MZ, O'Connor SM, van Holst Pellekaan NG, Young GP, James RJ. Reduced accumulation of specific microRNAs in colorectal neoplasia. Mol Cancer Res 2003; 1: 882-891.

32 Johnson SM, Grosshans H, Shingara J, Byrom M, Jarvis R, Cheng A et al. RAS is regulated by the let-7 microRNA family. Cell 2005; 120: 635-647.

33 Takamizawa J, Konishi H, Yanagisawa K, Tomida S, Osada H, Endoh $\mathrm{H}$ et al. Reduced expression of the let-7 microRNAs in human lung cancers in association with shortened postoperative survival. Cancer Res 2004; 64: 3753-3756.

34 Metzler M, Wilda M, Busch K, Viehmann S, Borkhardt A. High expression of precursor microRNA-155/BIC RNA in children with Burkitt lymphoma. Genes Chromosomes Cancer 2004; 39: 167-169.

35 Tam W, Hughes SH, Hayward WS, Besmer P. Avian bic, a gene isolated from a common retroviral site in avian leukosis virusinduced lymphomas that encodes a noncoding RNA, cooperates with c-myc in lymphomagenesis and erythroleukemogenesis. J Virol 2002; 76: 4275-4286.

36 O'Donnell KA, Wentzel EA, Zeller KI, Dang CV, Mendell JT. c-Myc-regulated microRNAs modulate E2F1 expression. Nature 2005; 435: 839-843.

37 He L, Thomson JM, Hemann MT, Hernando-Monge E, Mu D, Goodson $\mathrm{S}$ et al. A microRNA polycistron as a potential human oncogene. Nature 2005; 435: 828-833.

38 Cai X, Lu S, Zhang Z, Gonzalez CM, Damania B, Cullen BR. Kaposi's sarcoma-associated herpesvirus expresses an array of viral microRNAs in latently infected cells. Proc Natl Acad Sci USA 2005; 102: 5570-5575.

39 Pfeffer S, Sewer A, Lagos-Quintana M, Sheridan R, Sander C, Grasser FA et al. Identification of microRNAs of the herpesvirus family. Nat Methods 2005; 2: 269-276.

40 Omoto S, Fujii YR. Regulation of human immunodeficiency virus 1 transcription by nef microRNA. J Gen Virol 2005; 86: 751-755.

41 Sullivan CS, Grundhoff AT, Tevethia S, Pipas JM, Ganem D. SV40encoded microRNAs regulate viral gene expression and reduce susceptibility to cytotoxic T cells. Nature 2005; 435: 682-686.

42 Omoto S, Ito M, Tsutsumi Y, Ichikawa Y, Okuyama H, Brisibe EA et al. HIV-1 nef suppression by virally encoded microRNA. Retrovirology 2004; 1: 44.

43 Couturier JP, Root-Bernstein RS. HIV may produce inhibitory microRNAs (miRNAs) that block production of CD28, CD4 and some interleukins. J Theor Biol 2005; 235: 169-184.

44 Meister G, Tuschl T. Mechanisms of gene silencing by doublestranded RNA. Nature 2004; 431: 343-349.

45 Lecellier $\mathrm{CH}$, Dunoyer P, Arar K, Lehmann-Che J, Eyquem S, Himber $\mathrm{C}$ et al. A cellular microRNA mediates antiviral defense in human cells. Science 2005; 308: 557-560. 
46 Lu S, Cullen BR. Adenovirus VA1 noncoding RNA can inhibit small interfering RNA and MicroRNA biogenesis. J Virol 2004; 78: $12868-12876$

47 Famulok M, Mayer G. Intramers and aptamers: applications in protein-function analyses and potential for drug screening. Chembiochem 2005; 6: 19-26.

48 Jin P, Alisch RS, Warren ST. RNA and microRNAs in fragile $X$ mental retardation. Nat Cell Biol 2004; 6: 1048-1053.

49 Caudy AA, Myers M, Hannon GJ, Hammond SM. Fragile $X$-related protein and VIG associate with the RNA interference machinery. Genes Dev 2002; 16: 2491-2496.

50 Ishizuka A, Siomi MC, Siomi H. A Drosophila fragile X protein interacts with components of RNAi and ribosomal proteins. Genes Dev 2002; 16: 2497-2508.

51 Jin P, Zarnescu DC, Ceman S, Nakamoto M, Mowrey J, Jongens TA et al. Biochemical and genetic interaction between the fragile $\mathrm{X}$ mental retardation protein and the microRNA pathway. Nat Neurosci 2004; 7: 113-117.

52 Mourelatos Z, Dostie J, Paushkin S, Sharma A, Charroux B, Abel L et al. miRNPs: a novel class of ribonucleoproteins containing numerous microRNAs. Genes Dev 2002; 16: 720-728.

53 Gregory RI, Yan KP, Amuthan G, Chendrimada T, Doratotaj B, Cooch $\mathrm{N}$ et al. The Microprocessor complex mediates the genesis of microRNAs. Nature 2004; 432: 235-240.

54 Landthaler $\mathrm{M}$, Yalcin A, Tuschl T. The human DiGeorge syndrome critical region gene 8 and its D. melanogaster homolog are required for miRNA biogenesis. Curr Biol 2004; 14: 2162-2167.

55 Iwai N, Naraba H. Polymorphisms in human pre-miRNAs. Biochem Biophys Res Commun 2005; 331: 1439-1444.

56 Zeng Y, Yi R, Cullen BR. MicroRNAs and small interfering RNAs can inhibit mRNA expression by similar mechanisms. Proc Natl Acad Sci USA 2003; 100: 9779-9784.

57 Ganju P, Hall J. Potential applications of siRNA for pain therapy. Expert Opin Biol Ther 2004; 4: 531-542.

58 Lee YS, Kim HK, Chung S, Kim KS, Dutta A. Depletion of human micro-RNA miR-125b reveals that it is critical for the proliferation of differentiated cells but not for the downregulation of putative targets during differentiation. J Biol Chem 2005; 280: 16635-16641.

59 Boutla A, Delidakis C, Tabler M. Developmental defects by antisense-mediated inactivation of micro-RNAs 2 and 13 in Drosophila and the identification of putative target genes. Nucleic Acids Res 2003; 31: 4973-4980.

60 Hutvagner G, Simard MJ, Mello CC, Zamore PD. Sequencespecific inhibition of small RNA function. PLoS Biol 2004; 2: E98.

61 Devi GR, Beer TM, Corless CL, Arora V, Weller DL, Iversen PL. In vivo bioavailability and pharmacokinetics of a c-MYC antisense phosphorodiamidate morpholino oligomer, AVI-4126, in solid tumors. Clin Cancer Res 2005; 11: 3930-3938.

62 Henry SP, Geary RS, Yu R, Levin AA. Drug properties of secondgeneration antisense oligonucleotides: how do they measure up to their predecessors? Curr Opin Invest Drugs 2001; 2: 1444-1449.

63 Friedman KJ, Kole J, Cohn JA, Knowles MR, Silverman LM, Kole R. Correction of aberrant splicing of the cystic fibrosis transmembrane conductance regulator (CFTR) gene by antisense oligonucleotides. J Biol Chem 1999; 274: 36193-36199.

64 Mani S, Goel S, Nesterova M, Martin RM, Grindel JM, Rothenberg ML et al. Clinical studies in patients with solid tumors using a second-generation antisense oligonucleotide (GEM 231) targeted against protein kinase A type I. Ann N Y Acad Sci 2003; 1002: 252-262.

65 Cheng AM, Byrom MW, Shelton J, Ford LP. Antisense inhibition of human miRNAs and indications for an involvement of miRNA in cell growth and apoptosis. Nucleic Acids Res 2005; 33: 1290-1297.
66 Martin P. A New Access to 2-O-Alkylated Ribonucleosides and Properties of 2-O-Alkylated Oligoribonucleotides. Helvetica Chim Acta 1995; 78: 486-504.

67 Karras JG, McKay RA, Dean NM, Monia BP. Deletion of individual exons and induction of soluble murine interleukin-5 receptor-alpha chain expression through antisense oligonucleotide-mediated redirection of pre-mRNA splicing. Mol Pharmacol 2000; 58: 380-387.

68 Baker BF, Lot SS, Condon TP, Cheng-Flournoy S, Lesnik EA, Sasmor HM et al. 2'-O-(2-Methoxy)ethyl-modified anti-intercellular adhesion molecule 1 (ICAM-1) oligonucleotides selectively increase the ICAM-1 mRNA level and inhibit formation of the ICAM-1 translation initiation complex in human umbilical vein endothelial cells. J Biol Chem 1997; 272: 11994-12000.

69 Gleave ME, Monia BP. Antisense therapy for cancer. Nat Rev Cancer 2005; 5: 468-479.

70 Vester B, Wengel J. LNA (locked nucleic acid): high-affinity targeting of complementary RNA and DNA. Biochemistry 2004; 43: 13233-13241.

71 Childs JL, Disney MD, Turner DH. Oligonucleotide directed misfolding of RNA inhibits Candida albicans group I intron splicing. Proc Natl Acad Sci USA 2002; 99: 11091-11096.

72 Elayadi AN, Braasch DA, Corey DR. Implications of highaffinity hybridization by locked nucleic acid oligomers for inhibition of human telomerase. Biochemistry 2002; 41: 9973-9981.

73 Mouritzen P, Nielsen AT, Pfundheller HM, Choleva Y, Kongsbak L, Moller S. Single nucleotide polymorphism genotyping using locked nucleic acid (LNA). Expert Rev Mol Diagn 2003; 3: 27-38.

74 Fluiter $\mathrm{K}$, ten Asbroek $\mathrm{AL}$, de Wissel $\mathrm{MB}$, Jakobs $\mathrm{ME}$, Wissenbach $\mathrm{M}$, Olsson $\mathrm{H}$ et al. In vivo tumor growth inhibition and biodistribution studies of locked nucleic acid (LNA) antisense oligonucleotides. Nucleic Acids Res 2003; 31: 953-962.

75 Valoczi A, Hornyik C, Varga N, Burgyan J, Kauppinen S, Havelda Z. Sensitive and specific detection of microRNAs by northern blot analysis using LNA-modified oligonucleotide probes. Nucleic Acids Res 2004; 32: e175.

76 Chan JA, Krichevsky AM, Kosik KS. MicroRNA-21 is an antiapoptotic factor in human glioblastoma cells. Cancer Res 2005; 65: 6029-6033.

77 Lim LP, Lau NC, Garrett-Engele P, Grimson A, Schelter JM, Castle $\mathrm{J}$ et al. Microarray analysis shows that some microRNAs downregulate large numbers of target mRNAs. Nature 2005; 433: 769-773.

78 Robins H, Li Y, Padgett RW. Incorporating structure to predict microRNA targets. Proc Natl Acad Sci USA 2005; 102: 4006-4009.

79 John B, Enright AJ, Aravin A, Tuschl T, Sander C, Marks DS. Human MicroRNA targets. PLoS Biol 2004; 2: e363.

80 Krek A, Grun D, Poy MN, Wolf R, Rosenberg L, Epstein EJ et al. Combinatorial microRNA target predictions. Nat Genet 2005; 37: 495-500

81 Lewis BP, Burge CB, Bartel DP. Conserved seed pairing, often flanked by adenosines, indicates that thousands of human genes are microRNA targets. Cell 2005; 120: 15-20.

82 Esquela-Kerscher A, Slack FJ. The age of high-throughput microRNA profiling. Nat Methods 2004; 1: 106-107.

83 Lu J, Getz G, Miska EA, Alvarez-Saavedra E, Lamb J, Peck D et al. MicroRNA expression profiles classify human cancers. Nature 2005; 435: 834-838.

84 Beal J. Silence is golden: can RNA interference therapeutics deliver? Drug Discov Today 2005; 10: 169-172.

85 de Fougerolles A, Manoharan M, Meyers R, Vornlocher HP. RNA interference in vivo: toward synthetic small inhibitory RNA-based therapeutics. Methods Enzymol 2005; 392: 278-296. 